LPPM UNIHAZ $\quad \begin{gathered}\text { ABDIHAZ: Jurnal Ilmiah Pengabdian pada Masyarakat } \\ \text { https://journals.unihaz.ac.id/index.php/abdihaz }\end{gathered}$

\title{
Pelatihan Bahasa Inggris dan Pengelolaan Mangrove untuk Pemberdayaan Karang Taruna dalam Pengembangan Objek Wisata Mangrove
}

\section{Training of English Language and Mangrove Management for Youth Empowerment in Mangrove Tourism Object Development}

\author{
Mirna Yunita ${ }^{1 *}$, Yuneva $^{2}$, Fevi Wira Citra ${ }^{1}$, Elva Utami ${ }^{2}$, Warsa Sugandi ${ }^{1}$, Zairin ${ }^{1}$, Muhammad \\ alfi $^{1}$ \\ ${ }^{1}$ Program Studi Pendidikan Geografi, Universitas Prof. Dr. Hazairin SH, Jl. Jend. A. Yani No. 1 Bengkulu, Indonesia \\ ${ }^{2}$ Program Studi Pendidikan Bahasa Inggris, Universitas Prof. Dr. Hazairin SH, Jl. Jend. A. Yani No. 1 Bengkulu, \\ Indonesia
}

\begin{tabular}{l}
\hline Info Artikel \\
\hline Diterima 10 Juni 2021 \\
Ditelaah 30 September 2021 \\
Disetujui 01 Desember 2021 \\
Tersedia daring 30 Desember \\
2021 \\
*Penulis untuk \\
korespondensi \\
mirnayunita859@ gmail.com \\
\hline
\end{tabular}

Kata Kunci:

Bahasa Inggris,

Mangrove,

Obyek Wisata

\begin{abstract}
ABSTRAK
Karang taruna merupakan organisasi pemuda di lingkungan kelurahan/desa. Pengabdian pada masyarakat ini bertujuan untuk melatih dan mengedukasi remaja karang taruna di Kelurahan Sumber Jaya Kota Bengkulu agar memiliki kemampuan berbahasa Inggris yang dapat digunakan untuk memandu wisatawan asing dan memiliki pengetahuan mengenai mangrove serta pengelolaan mangrove untuk kegiatan ekowisata. Kegiatan dilakukan dengan tiga tahap: 1) tahap persiapan; 2) tahap perencanaan; 3) tahap pelaksanaan. Pada tahap ketiga, evaluasi dilaksanakan melalui praktek berbicara bahasa Inggris dan menyebarkan angket mengenai kemampuan berbahasa Inggris dan pengetahuan mengenai mangrove. Hasil evaluasi menunjukkan bahwa: 1) $100 \%$ peserta dapat memberikan salam dan memperkenalkan diri dalam bahasa Inggris; 2) $90 \%$ peserta mampu memberikan informasi tempat yang menarik dalam bahasa Inggris; 3) 90\% peserta mampu bertanya dan menjawab dalam bahasa Inggris; 4) $100 \%$ peserta mampu memberikan informasi objek wisata dalam bahasa Inggris; 5) $100 \%$ peserta dapat menjelaskan mengenai aturan berwisata dalam bahasa Inggris; 6) $100 \%$ peserta dapat memberikan jawaban mengenai objek wisata; 7) 100\% peserta dapat menyampaikan kalimat suka dan tidak suka; 8) 100\% peserta dapat menerima tamu; 9) 90\% peserta menjelaskan cara pembuatan pupuk organik; 10) $90 \%$ peserta tahu cara menjelaskan pembuatan kerajinan tangan; 11) $100 \%$ peserta memahami fungsi, potensi dan jenis hutan mangrove; 12) $90 \%$ peserta mengetahui pengelolaan wisata berbasis konservasi mangrove; 13) 90\% peserta memahami penjagaan dan peningkatan kualitas mangrove; 14) $100 \%$ peserta memahami pengelolaan melalui diversifikasi wisata; 15) $90 \%$ peserta mengenal sarana prasaran wisata mangrove; 16) $100 \%$ peserta mampu mengolah potensi mangrove menjadi oleh-oleh. Kesimpulan dari evaluasi kegiatan pengabdian ini adalah remaja karang taruna memahami teknik berbahasa Inggris khusus memandu wisata dan memiliki pemahaman mengenai mangrove.
\end{abstract}

\section{ABSTRACT}

Karang taruna is a youth organization in a village. This community service program was aimed to train Karang Taruna member in Sumber Jaya Village, Kota Bengkulu speaking English which can be used to guide foreign tourists and and to educate them about mangroves and its management for ecotourism activities. The activity was carried out in three stages: 1) the preparation; 2) the
English,

Mangrove,

Tourism object 
planning; 3) the implementation stage. In the third stage, an evaluation was carried out through the practice of speaking English and distributing questionnaires about English language skills and knowledge about mangroves. After the service activities were carried out, the results showed that the participants: 1) 100\% understood how to greet and introduce in English; 2) $90 \%$ could explain the information about interest place in English; 3) 90\% could ask and answer in English; 4) 100\% could explain about tourism object in English; 5) $100 \%$ could explain about the rules of travel in English; 6) $100 \%$ could answer about tourism object; 7) 100\% could convey likes and dislikes; 8) 100\% could hosting; 9) $90 \%$ could explain how to make organic fertilizers; 10) $90 \%$ could explain the making of handicrafts; 11) $100 \%$ understood the function, potential and types of mangrove forests; 12) $90 \%$ knew the tourism management based on mangrove conservation; 13) $90 \%$ understood maintenance and improvement of mangrove quality; 14) $100 \%$ understood management through tourism diversification; 15) $90 \%$ understood mangrove tourism infrastructure; 16) $100 \%$ understood the potential of mangroves that can be processed into souvenirs. The results of the service can be concluded that the Karang Taruna members have understood about English language technique specifically to tour guide and had an understanding of mangroves.

ISSN 2685-0354 (Media Online). Diterbitkan oleh Universitas Prof. Dr. Hazairin, SH. Ini merupakan jurnal bebas akses di bawah lisensi Creative Commons Atribution 4.0 International.

\section{PENDAHULUAN}

Pariwisata adalah kegiatan perjalanan sekelompok orang atau seseorang ke suatu daerah yang memiliki daya tarik baik alamnya, kebudayaan maupun sejarahnya dan didukung dengan segala fasilitas yang ada di destinasi wisata tersebut. Wisatawan mendapatkan pengalaman dari perjalanannya tersebut yang tidak dirasakan selama berada di tempat tinggal. Untuk itu, diperlukan dukungan pemerintah, masyarakat dan pengusaha dalam pengembangan pariwisata (Yunita, 2014)

Salah satu dukungan yang termasuk berpengaruh adalah dukungan dari generasi milenial karena generasi ini adalah generasi yang akan melanjutkan pembangunan di segala bidang. Salah satunya adalah pembangunan di bidang pengelolaan pariwisata. Dukungan generasi muda terhadap pariwisata dapat berupa pengembangan atraksi, fasilitas yang dibutuhkan, maupun menjaga kelestarian lingkungan pariwisata.

Kota Bengkulu merupakan wilayah yang memiliki beragam potensi wisata yang telah dikelola oleh pemerintah bersama masyarakat. Pengelolaan ini telah berdampak positif bagi pemerintah yaitu bertambahnya Pendapatan Asli Daerah (PAD) dan pendapatan masyarakat. Namun, pengelolaanya belum melibatkan generasi milenial khususnya generasi muda disekitar obyek wisata.

Salah satu potensi wisata yang dimiliki Kota Bengkulu yaitu Hutan mangrove. Hutan mangrove memiliki peranan penting dalam tumbuh kembang perikanan pantai (Heriyanto \& Subiandono, 2012). Selanjutnya, ekosistem mangrove berperan dalam mencegah terjadinya berbagai bencana misalnya sebagai peredam gelombang, pelindung pantai dari abrasi, pemecah ombak, perangkap sedimen yang diangkut oleh aliran air permukaan, dan pencegah intruisi air laut kedaratan (Utomo, 2017).

Namun, hutan mangrove yang ada di Bengkulu telah mengalami kerusakan. Berdasarkan data penelitian yang dilakukan oleh Anggraini (2014) 13 tahun (2000-2013), kerusakan hutan mangrove di kawasan Pantai Panjang dan Pulau Baai mencapai 65\%. Kerusakan ini disebabkan oleh prilaku manusia. Ekowisata mangrove merupakan cara yang tepat untuk mencegah bertambahnya kerusakan mangrove di Kota Bengkulu. Karena, ekowisata adalah strategi 
pengelolaan yang memberikan ambang batas laju pemanfaatan ekosistem alamiah dan buatan, serta sumber daya alam yang ada di dalamnya (Tuwo, 2011).

Pengembangan ekowisata mangrove membutuhkan sarana dan prasarana yang dapat menarik minat wisatawan untuk datang dan menggunakan uangnya khususnya wisatawan asing. Bahasa inggris dan pengetahuan mengenai mangrove perlu dipahami generasi milenial agar wisatawan asing betah tinggal di daerah yang dikunjunginya. Hal ini juga dapat dijadikan cara untuk mendukung program pemerintah Provinsi Bengkulu yaitu program "Visit Wonderful Bengkulu2020”. Program ini merupakan program wisata yang bukan hanya menarik minat wisatawan nasional tetapi juga minat wisatawan internasional.

Hasil observsi awal di lapangan melalui interview terhadap beberapa pemuda di Kelurahan Sumber Jaya di Pulau Baai, Kota Bengkulu (Minggu, 20 Januari 2019), menunjukkan bahwa mereka belum memiliki pemahaman atau pengetahuan dalam mendukung pengembangan ekowisata mangrove baik dalam berbahasa Inggris yang dapat digunakan memandu wisatawan yang berasal dari luar negeri maupun pengelolaan potensi mangrove untuk kegiatan wisata. Mereka belum pernah mendapatkan pemberdayaan dari pihak manapun. Selain itu, mereka menganggap belajar bahasa Inggris adalah pembelajaran yang sulit untuk dipahami dan membutuhkan dana yang besar untuk ikut kursus bahasa Inggris. Generasi muda di Kelurahan Sumber Jaya yang berada di kawasan Pulau Baai Kota Bengkulu juga belum memiliki pemahaman yang baik mengenai peranan ekosistem mangrove bagi kehidupan dan pemanfaatan potensi ekowisata dalam mendukung pengembangan ekowisata hutan mangrove.

Berdasarkan hasil analisis situasi yang telah dilakukan di lokasi mitra, dapat disimpulkan bahwa permasalahan yang dihadapi oleh mitra adalah: 1) Masih rendahnya keterampilan dan pengetahuan pemuda di Kelurahan Sumber Jaya dalam berbahasa Inggris. Kondisi ini tidak mendukung perkembangan ekowisata mangrove jika ada wisatawan yang berasal dari luar negeri. Untuk itu, diperlukan motivasi kepada generasi muda di Kelurahan Sumber Jaya bahwa kemamampuan berkomunikasi dalam bahasa Inggris sangat penting dalam mendukung pengembangan pariwisata; 2) Keterbatasan dana untuk menyewa jasa tenaga pengajar bahasa Inggris salah satu permasalahan yang dihadapi pemuda di Kelurahan Sumber Jaya, selain itu motivasi untuk terampil berbahasa inggris harus selalu didukung; 3) Pengetahuan generasi pemuda di Kelurahan Sumber Jaya mengenai peranan ekosistem mangrove bagi kehidupan masih rendah. Hal ini rentan terhadap kesalahan pengelolaan yang dapat berdampak negatif; 4) Belum antusiasnya generasi muda di Kelurahan Sumber Jaya dalam menganalisis dan berupaya mengembangkan potensi ekowisata mangrove.

Hasil observasi tersebut menarik penulis melakukan kegiatan pengabdian pada masyarakat dalam bentuk pelatihan berbahasa Inggris untuk memandu wisatawan asing dan memberikan pengetahuan mengenai mangrove dan pengelolaannya. untuk kegiatan kepariwisataan dengan tujuan generasi milenial khususnya generasi karang taruna bisa berbahasa inggris dan memiliki pengetahuan tentang mangrove. Solusi yang ditawarkan untuk mengatasi permasalahan yang dihadapi mitra oleh generasi pemuda di Kelurahan Sumber Jaya, yaitu: 1) Melakukan sosialisasi dan support kepada pemuda mengenai pentingnya memiliki kemampuan berbahasa inggris dalam mendukung pengembangan pariwisata, khususnya pemandu wisatawan mancanegara; 2) Melakukan pelatihan bahasa inggris kepada pemuda di Kelurahan Sumber Jaya dengan materi yang berkaitan dengan memandu wisatawan mancanegara. Pembelajaran bahasa inggris yang akan dilaksanakan dalam pelatihan ini adalah pelatihan bahasa inggris untuk tujuan khusus, yaitu: 
English for Speccific Purpose (ESP). ESP adalah pola pembelajaran bahasa Inggris yang materinya untuk tujuan khusus (Hutchinson \& Waters, 1987); 3) Melakukan sosialisasi kepada pemuda di Kelurahan Sumber Jaya mengenai peranan mangrove dan bagaimana menjaga kelestarian hutan mangrove.

\section{METODE}

Kegiatan pengabdian pada masyarakat ini dilaksanakan di Kelurahan Sumber Jaya Kota Bengkulu selama 3 bulan dari bulan Mei sampai Juli 2019. Kegiatan dilaksanakan dalam beberapa tahap, yaitu:

\section{Tahap persiapan}

Survei lapangan dilakukan ke lokasi mitra pada tahapan ini. Survei bertujuan untuk mendapatkan informasi melalui observasi dengan melihat situasi/keadaan dan mengidentifikasi masalah-masalah yang dihadapi mitra. Hasil observasi dianalisa untuk menentukan strategi mengatasi masalah yang dihadapi mitra.

\section{Tahap perencanaan}

Berdasarkan hasil observasi awal, suatu rancangan pembelajaran disusun untuk diberikan kepada generasi muda. Rancangan tersebut disusun melalui beberapa tahapan: (1) merumuskan tujuan pembelajaran yaitu konsep pembelajaran sebagai pemandu wisata yang mampu berkomunikasi bahasa inggris dan generasi muda yang memahami pengelolaan wisata yang berbasis lingkungan; (2) menentukan keterampilan berkomunikasi berbahasa Inggris yang lebih fokus kepada Speaking dan generasi yang mampu mengelola wisata mangrove yang ramah lingkungan (3) menetukan metode pembelajaran yang lebih berfokus kepada siswa dengan kegiatan pembelajaran yang berupa bermain peran (role play), diskusi dalam kelompok kecil, bekerja secara berpasangan dan presentasi (Susanti \& Rukiati, 2017).

\section{Tahap pelaksanaan}

Sosialisasi mengenai pentingnya menguasai bahasa Inggris dan memahami potensi sumber daya alam hutan mangrove bagi lingkungan dan kehidupan manusia dilaksanakan di balai Kelurahan Sumber Jaya pada bulan Mei hingga September 2019 yang dihadiri oleh pemuda karang taruna Kelurahan Sumber Jaya. Tim pelaksana memberikan motivasi dan pemahaman pentingnya belajar dan dalam kegiatan pembelajaran pasti mengalami hambatan.

Kegiatan selanjutnya adalah pelatihan berbahasa Inggris selama 8 kali pertemuan dengan rincian 5 kali untuk pelatihan bahasa Inggris dan 3 kali pertemuan untuk kegiatan pemahaman dalam pengembangan obyek wisata mangrove. Metode pembelajaran yang digunakan dalam pelatihan ini adalah metode kooperatif. Pembelajaran yang lebih berfokus kepada peserta didik.

Pembelajaran yang diberikan dalam pelatihan bahasa Inggris adalah materi dasar. Beberapa topik dalam materi pelatihan Bahasa Inggris adalah greeting and introducing; giving information about place of interst; asking and anwering required question; describing objects and giving instructions; explaining safety, rules and etiquette; asking about and giving directions; likes, dislikes and preferences; welcoming guests in tubing area; explaining the procedure of making organicc fertilizer; explaining procedure of making handycraft (Susanti \& Rukiati, 2017).

Materi untuk pengelolaan potensi wisata hutan mangrove adalah tentang hutan mangrove dan cara pengelolaan mangrove untuk kegiatan wisata. Di antara topik materi yang diberikan 
adalah fungsi, potensi hutan mangrove, dan jenis hutan mangrove; pengelolaan berbasis konservasi mangrove; pengelolaan dalam hal penjagaan dan peningkatan kualitas sumberdaya mangrove; pengelolaan melalui diversifikasi wisata mangrove; pengelolaan sarana prasaran wisata mangrove; dan potensi mangrove yang dapat dikelola menjadi produk oleh-oleh.

Evaluasi dilakukan melalui praktek berbicara bahasa inggris dan menyebarkan angket mengenai kemampuan berbahasa inggris dan pengetahuan mengenai mangrove. Evaluasi ditujukan untuk mengetahui keberhasilan pelaksanaan kegiatan dan penerimaan peserta terhadap materi yang diberikan.

\section{HASIL DAN PEMBAHASAN}

Kegiatan pengabdian dilaksanakan melibatkan mitra Karang Taruna Kelurahan Sumber Jaya Kota Bengkulu. Para peserta antusias mengikuti pelatihan (Gambar 1) dan mengalami perubahan pengetahuan mengenai Bahasa Inggris dan mangrove.

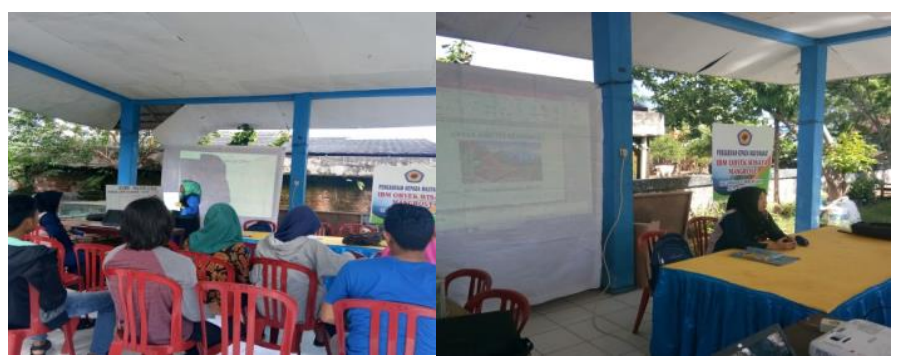

Gambar 1 Kegiatan pelatihan di Balai Kelurahan Sumber Jaya Kota Bengkulu

Tabel 1 Kondisi kemampuan dan pemahaman Bahasa Inggris peserta sebelum kegiatan

\begin{tabular}{|c|c|c|c|}
\hline \multirow{2}{*}{ No } & \multirow{2}{*}{ Indikator } & \multicolumn{2}{|c|}{ Persentase Jawaban } \\
\hline & & $\mathrm{Ya}$ & Tidak \\
\hline 1 & $\begin{array}{l}\text { Memahami cara memberikan salam dan memperkenalkan diri dalam Bahasa } \\
\text { Inggris (greeting and introduction) }\end{array}$ & $40 \%$ & $60 \%$ \\
\hline 2 & $\begin{array}{l}\text { Memahami cara memberitahukan tempat yang menarik dalam bahasa Inggris } \\
\text { (giving information about place of interest) }\end{array}$ & $20 \%$ & $80 \%$ \\
\hline 3 & $\begin{array}{l}\text { Memahami cara menjawab dan bertanya dalam bahasa Inggris (Asking and } \\
\text { answering required question) }\end{array}$ & $20 \%$ & $80 \%$ \\
\hline 4 & $\begin{array}{l}\text { Memahami cara memberikan informasi tentang objek wisata dalam bahasa Inggris } \\
\text { (Describing objects and giving instructions) }\end{array}$ & $10 \%$ & $90 \%$ \\
\hline 5 & $\begin{array}{l}\text { Memahami cara menjelaskan mengenai etika dan aturan-aturan ketika berada di } \\
\text { tempat objek wisata dalam bahasa Inggris (Explaining safety, rules and etiquette) }\end{array}$ & $10 \%$ & $90 \%$ \\
\hline 6 & $\begin{array}{l}\text { Memahami cara memberikan jawaban mengenai objek wisata dalam bahasa } \\
\text { Inggris (Asking about and giving direction) }\end{array}$ & $10 \%$ & $90 \%$ \\
\hline 7 & $\begin{array}{l}\text { Memahami penyataan kalimat suka dan tidak suka dalam bahasa Inggris (Likes, } \\
\text { dislikes and preferences) }\end{array}$ & $20 \%$ & $80 \%$ \\
\hline 8 & $\begin{array}{l}\text { Memahami kalimat dalam menerima tamu di area wisata dalam bahasa Inggris } \\
\text { (Welcoming guests in tubing area) }\end{array}$ & $10 \%$ & $90 \%$ \\
\hline 9 & $\begin{array}{l}\text { Memahami cara menjelaskan prosedur dalam pembuatan pupuk organik } \\
\text { (Explaining the procedure of making organicc fertilizer) }\end{array}$ & - & - \\
\hline & $\begin{array}{l}\text { Memahami cara menyampaikan prosedur dalam pembuatan kerajinan tangan } \\
\text { dalam bahasa Inggris (Explaining procedure of making handycraft) }\end{array}$ & - & - \\
\hline
\end{tabular}


Remaja karang taruna di Kelurahan Sumber Jaya umumnya belum memahami bahasa Inggris yang dapat digunakan untuk memandu wisata. Kondisi ini merupakan kondisi sebelum kegiatan pengabdian pada masyarakat ini dilaksanakan (Tabel 1). Ini merupakan alasan pentingnya dilaksanakan kegiatan pelatihan Bahasa Inggris dasar untuk pemandu wisata. Materi dan cara melatih dirancang sedemikian rupa mengingat keberagaman latar belakang peserta. Nara sumber yang merupakan tim pengabdi memberikan materi dengan menarik dan kreatif sehingga peserta antusian mengikuti kegiatan hingga selesai. Dialog yang interaktif dan latihan yang terarah diterapkan dalam kegiatan ini. Setiap peserta dilatih untuk berani menyampaikan kalimat-kalimat dasar dalam perkenalan dan percakapan sehari-hari. Tugas diberikan sehingga para peserta terdorong untuk mengingat dan mempraktekkan Bahasa Inggris di rumah masing-masing hingga berkumpul lagi dapa jadwal pelatihan berikutnya.

Pelatihan dan pendampingan dengan berbagai metode menarik yang dilakukan dalam kegiatan pengabdian pada masyarakat ini menambah pengetahuna berbahasa Inggris para peserta. Setelah dilakukan rangkaian pelatihan, remaja karang taruna di Kelurahan Sumber Jaya mengalami perubahan yaitu umumnya remaja sudah bisa menggunakan bahasa Inggris untuk kegiatan memandu wisatawan (turis asing). Hal ini dapat diamati ketika praktek berbahasa Inggris dan juga hasil angket evaluasi diakhir kegiatan. Hasil evaluasi menunjukan bahwa 90-100 remaja karang taruna bisa menggunakan bahasa inggris untuk kegiatan memandu wisatawan asing (Tabel 2).

Tabel 2 Kondisi kemampuan dan pemahaman Bahasa Inggris peserta setelah kegiatan

\begin{tabular}{|c|c|c|c|}
\hline \multirow{2}{*}{ No } & \multirow{2}{*}{ Indikator } & \multicolumn{2}{|c|}{ Persentase Jawaban } \\
\hline & & Ya & Tidak \\
\hline 1 & $\begin{array}{l}\text { Memahami cara memberikan salam dan memperkenalkan diri dalam } \\
\text { Bahasa Inggris (greeting and introduction) }\end{array}$ & $100 \%$ & - \\
\hline 2 & $\begin{array}{l}\text { Memahami cara memberitahukan tempat yang menarik dalam bahasa } \\
\text { Inggris (giving information about place of interest) }\end{array}$ & $90 \%$ & $10 \%$ \\
\hline 3 & $\begin{array}{l}\text { Memahami cara menjawab dan bertanya dalam bahasa Inggris (Asking } \\
\text { and answering required question) }\end{array}$ & $90 \%$ & $10 \%$ \\
\hline 4 & $\begin{array}{l}\text { Memahami cara memberikan informasi tentang objek wisata dalam } \\
\text { bahasa Inggris (Describing objects and giving instructions) }\end{array}$ & $100 \%$ & - \\
\hline 5 & $\begin{array}{l}\text { Memahami cara menjelaskan mengenai etika dan aturan-aturan ketika } \\
\text { berada di tempat objek wisata dalam bahasa Inggris (Explaining safety, } \\
\text { rules and etiquette) }\end{array}$ & $100 \%$ & - \\
\hline 6 & $\begin{array}{l}\text { Memahami cara memberikan jawaban mengenai objek wisata dalam } \\
\text { bahasa Inggris (Asking about and giving direction) }\end{array}$ & $100 \%$ & - \\
\hline 7 & $\begin{array}{l}\text { Memahami penyataan kalimat suka dan tidak suka dalam bahasa Inggris } \\
\text { (Likes, dislikes and preferences) }\end{array}$ & $100 \%$ & - \\
\hline 8 & $\begin{array}{l}\text { Memahami kalimat dalam menerima tamu di area wisata dalam bahasa } \\
\text { Inggris (Welcoming guests in tubing area) }\end{array}$ & $100 \%$ & - \\
\hline 9 & $\begin{array}{l}\text { Memahami cara menjelaskan prosedur dalam pembuatan pupuk organik } \\
\text { (Explaining the procedure of making organicc fertilizer) }\end{array}$ & $90 \%$ & $10 \%$ \\
\hline 10 & $\begin{array}{l}\text { Memahami cara menyampaikan prosedur dalam pembuatan kerajinan } \\
\text { tangan dalam bahasa Inggris (Explaining procedure of making } \\
\text { handycraft) }\end{array}$ & $90 \%$ & $10 \%$ \\
\hline
\end{tabular}


Capaian kegiatan pengabdian dalam bidang Bahasa Inggris sebagaimana diuraikan di atas selaras dengan pendapat (Susanti, 2017) mengenai pemandu wisata. Kriteria seorang pemandu wisata harus memiliki pengetahuan dalam bahasa asing minimal bahasa Inggris khususnya untuk memandu wisata asing. Beberapa topik Bahasa Inggris yang telah dipahami oleh generasi milenial Kelurahan Sumber Jaya Kota Bengkulu adalah 1) Greeting and Introducing: 2) Giving information about place of interst; 3) Asking and anwering required question; 4) Describing objects and giving instructions; 5) Explaining Safety, Rules and Etiquette; 6) Asking about and giving directions; 7) Likes, dislikes and preferences; 8) Welcoming guests in tubing area; 9) Explaining the procedure of making organicc fertilizer; dan 10) Explaining procedure of making handycraft (Susanti, 2017).

Hasil survei awal menunjukkan bahwa umumnya peserta belum memahami mengenai fungsi, potensi dan bagaimana mengelola mangrove. Sebesar $90-100 \%$ peserta menjawab tidak paham dalam survei awal tersebut (Tabel 3).

Tabel 3 Kondisi pemahaman peserta mengenai mangrove sebelum kegiatan

\begin{tabular}{clcc}
\hline \multirow{2}{*}{ No } & \multicolumn{1}{c}{ Indikator } & \multicolumn{2}{c}{ Persentase Jawaban } \\
\cline { 3 - 4 } & & \multicolumn{1}{c}{ Ya } & Tidak \\
\hline 1 & Memahami fungsi, potensi dan jenis hutan mangrove & $10 \%$ & $90 \%$ \\
2 & Memahami pengelolaan wisata berbasis konservasi mangrove & $10 \%$ & $90 \%$ \\
3 & Memahami Pengelolaan dalam hal penjagaan dan peningkatan kualitas & - & $100 \%$ \\
& sumberdaya mangrove & & \\
4 & Memahami Pengelolaan melalui diversifikasi wisata mangrove & & $100 \%$ \\
5 & Memahami Pengelolaan sarana prasaran wisata mangrove & $100 \%$ \\
6 & Memahami Potensi mangrove yang dapat dikelola menjadi produk oleh- & $10 \%$ & $90 \%$ \\
& oleh & & \\
\hline
\end{tabular}

Tabel 4 Kondisi pemahaman peserta mengenai mangrove setelah kegiatan

\begin{tabular}{clcc}
\hline \multirow{2}{*}{ No } & & \multicolumn{1}{c}{ Indikator } & \multicolumn{2}{c}{ Persentase Jawaban } \\
\cline { 3 - 4 } & & \multicolumn{1}{c}{ Ya } & Tidak \\
\hline 1 & Memahami fungsi, potensi dan jenis hutan mangrove & $100 \%$ & - \\
2 & Memahami pengelolaan wisata berbasis konservasi mangrove & $90 \%$ & $10 \%$ \\
3 & Memahami Pengelolaan dalam hal penjagaan dan peningkatan kualitas & & \\
& sumberdaya mangrove & $90 \%$ & $10 \%$ \\
4 & Memahami Pengelolaan melalui diversifikasi wisata mangrove & $100 \%$ & - \\
5 & Memahami Pengelolaan sarana prasaran wisata mangrove & $90 \%$ & $10 \%$ \\
6 & Memahami Potensi mangrove yang dapat dikelola menjadi produk oleh- & & \\
& oleh & $100 \%$ & - \\
\hline
\end{tabular}

Setelah dilakukannya pengabdian dengan memberikan materi mengenai fungsi, potensi dan pengelolaan mangrove untuk kegiatan wisata, remaja karang taruna dikelurahan sumber jaya telah memiliki pengetahuan mengenai peranan mangrove. Sebesar $90-100 \%$ peserta kegiatan telah memahami potensi dan pengelolaan mangrove untuk wisata. Pengetahuan mengenai pengelolaan mangrove, untuk mencegah terjadinya kerusakan ekosistem mangrove, menurut Purwanti et al. (2017) dalam kegiatan kepariwisataan perlu di perhatikan pengelolaan ekosistem mangrove agar tidak terjadi kerusakan lingkungan, dan generasi muda kelurahan sumber jaya telah memahami materi pengelolaan hutan mangrove setelah dilakukan pengabdian, 6 hal yang harus dipahami oleh 
semua elemen termasuk generasi muda yaitu: 1) Fungsi, potensi hutan mangrove, dan jenis hutan mangrove; 2) Pengelolaan berbasis konservasi mangrove; 3) Pengelolaan dalam hal penjagaan dan peningkatan kualitas sumberdaya mangrove; 4) Pengelolaan melalui diversifikasi wisata mangrove; 5) Pengelolaan sarana prasaran wisata mangrove; 6) Potensi mangrove yang dapat dikelola menjadi produk oleh-oleh. (Purwanti et al, 2017).

\section{KESIMPULAN}

Kesimpulan yang dapat diambil dari evaluasi kegiatan pengabdian pada masyarakat yang telah dilaksanakan adalah terjadi perubahan pengetahuan dan kemampuan generasi milenial dalam hal berbahasa Inggris dan pengelolaan mangrove. Sebesar 90-100\% dari semua peserta menguasai tiap topik materi yang diberikan selama kegiatan pelatihan Bahasa Inggris dan pengelolaan mangrove. Namun, kegiatan lanjutan tetap diperlukan untuk kesinambungan dukungan terhadap pengembangan ekowisata mangrove di Pulau Baai Kota Bengkulu.

\section{DAFTAR PUSTAKA}

Anggraini, N. (2014). Valuasi ekonomi hutan mangrove akibat konversi lahan di Taman Wisata Alam Pantai Panjang dan Pulau Baai Bengkulu [Tesis]. Program Pascasarjana Universitas Gajah Mada.

Heriyanto, N. M., \& Subiandono, E. (2012). Komposisi dan struktur tegakan biomasa dan kondisi kandungan karbon hutan mangrove di Taman Nasional Alas Purwo. Jurnal Penelitian Hutan dan Konservasi Alam, 9(1), 23-32.

Hutchinson, T. \& Waters, A. (1987). English for Specific Purposes. A Learning-Centered Aprproach. Cambridge University.

Purwanti, P., Susilo, E., \& Indrayani, E. (2017). Pengelolaan hutan mangrove berkelanjutan : Pendekatan kelembagaan dan insentif ekonomi. UB Press.

Susanti, N. \& Rukiati, E. (2017). Pelatihan Bahasa Inggris bagi karang taruna di Desa Wisata lombok Kulon Bondowoso. Prosiding Seminar Nasional Pengabdian Kepada Masyarakat. Politeknik Negeri Jember.

Tuwo, A. (2011). Pengelolaan ekowisata pesisir dan laut: Pendekaran ekologi, sosial ekonomi, kelembagaan, dan sarana wilayah. Brilian Internasional

Utomo, B., Budiastuty, S., \& Muryani, C. (2017). Strategi pengelolaan hutan mangrove di Desa Tanggul Tlare Kecamatan Kedung Kabupaten Jepara. Jurnal Ilmu Lingkungan, 15(2), 117123

Yunita, M. (2014). Strategi pengembangan pariwisata Kabupaten Lahat Sumatera Selatan (Studi Kasus Objek Wisata TWA Bukit Serelo Kecamatan Merapi Selatan) [Tesis]. Program Pascasarjana Pendidikan Geografi Universitas Negeri Padang. 